\title{
SCALABLE MICROWAVE WASTE-TO-FUEL CONVERSION
}

\author{
M. Robinson ${ }^{1}$, Z. Popovic ${ }^{1}$ \\ ${ }^{1}$ Electrical, Computer and Energy Engineering, University of Colorado, Boulder, U.S.A. \\ Megan.Robinson@,colorado.edu,Zoya.Popovic@,colorado.edu
}

Keywords: microwave, pyrolysis, waste management, high-efficiency SSPAs

\section{Introduction}

This paper presents an efficiency study for scalable microwave waste management. When waste with carbon content is subjected to volume power densities on the order of $0.25 \mathrm{~W} / \mathrm{cm}^{3}$ at $\mathrm{GHz}$ frequencies, it converts to solid coke fuel with oil and gas bi-products that can further be for fuel, leaving no trace. For an efficient process, a well-controlled uniform RF field should be maintained in a non-uniform and time-variable material. We are developing a 2.45-GHz active microwave cavity with solid-state $(\mathrm{GaN})$ spatially power combined sources for lower volumes, Fig.1. In the energy balance calculations, the input energy into the system consists of the waste chemical energy and the DC electrical energy used to obtain the RF power with an efficiency that can reach $70 \%$ for $\mathrm{kW}$ power levels. The efficiency of RF power conversion to heating rate in the waste mass is calculated from full-wave simulations for four waste mixtures, input power, and operating temperature. The output energy estimates are collected from various pyrolysis process descriptions, e.g. [1], with the total energy being that of the solid fuel $(35 \mathrm{MJ} / \mathrm{kg})$ and oil caloric values, e.g. $40 \mathrm{MJ} / \mathrm{kg}$ for plastics and about $10-15 \mathrm{MJ} / \mathrm{kg}$ for non-plastics [2]. A byproduct is flue gas, which can be converted to synthetic gas fuel (Syngas) as described in, e.g. [3].

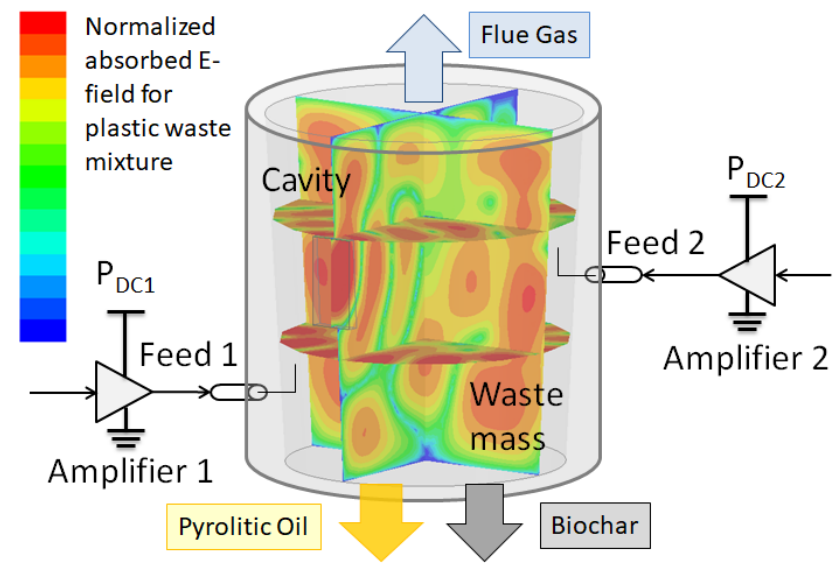

Fig. 1. Block diagram of an active microwave cavity for waste to fuel conversion. The cavity is fed by several power amplifiers with probe outputs. Absorption of microwave energy results in waste conversion into solid fuel (biochar), oil which can be converted to liquid fuel, and flue gas which can be converted to synthetic gas fuel. The relative phase between the feeds, mass mixing, frequency modulation and mode mixing can be used to ensure high uniformity of the electric field within the waste mass. 


\section{DC to RF Conversion}

The two methods to obtain $\mathrm{kW}$-level power at $\mathrm{GHz}$ frequencies are solid-state power amplifiers and tubes. In the $2 \mathrm{GHz}$ range, $\mathrm{GaN}$ transistors have demonstrated high power levels with high efficiency, e.g. [4],[5] and can be further power combined. Magnetrons have also been power combined with power combining efficiencies above $90 \%$ to achieve power levels around $30 \mathrm{~kW}[6]$. The analysis in this paper is not specific to a particular type of RF power generation, and is described by a conversion efficiency which is assumed to be $70 \%$.

\section{Electric Field Simulations}

The fields inside the waste volume produce heat through Joule losses. The thermal power produced in the cavity depends on the filling material properties, relative permittivity $\left(\varepsilon_{r}\right)$, conductivity $(\sigma)$, geometry of cavity and type of excitation, and is calculated from:

$$
P_{T h}=\iiint|E(x, y, z)|^{2} \sigma(x, y, z) d V
$$

It is desirable to keep the power density of Joule losses uniform through the heating process, because that usually results in the best time-average efficiency. This analysis was done using a single waveguide port excitation. There is a tradeoff between large volumes which can have a high level of field uniformity and small volumes which are effectively heated with a single feed. Several rectangular and cylindrical cavities, with volumes ranging from $0.0008 \mathrm{~m}^{3}$ to $0.15 \mathrm{~m}^{3}$, were compared using a full-wave eigen-mode solver (Ansys HFSS) to determine the modal content around the operating frequency of $2.45 \mathrm{GHz}$. The chosen cavity has the shape of an actual trash-can, cylindrical in shape and with one base larger, Fig.2. For the simulations, the radii of the bases are chosen to be $R_{l}=12.7 \mathrm{~cm}$ and $R_{2}=11.2 \mathrm{~cm}$, with a height of $H=28.2 \mathrm{~cm}$. The feed is an S-band (WR340) waveguide port with a lower edge $13 \mathrm{~cm}$ above the bottom of the cavity. A larger version of this system will include multiple waveguide ports that are strategically placed to uniformly excite the waste volume under varying permittivity and loss conditions.

Equation (1) can be simplified if the waste volume is assumed to consist of sub-volumes that have uniform conductivities, where the integral becomes a sum:

$$
P_{T h}=\sum_{k=0}^{n} \sigma|E(x, y, z)|^{2} \Delta V
$$

The fields can be found using a full-wave EM solver, given a specific geometry, electrical properties, and excitation. Plots of the magnitude of the electric field throughout the cavity are shown for two extremes of the four cases in Fig. 2. The breakdown of the food mixture was not detailed in reference [8] and for this analysis a mixture of $45 \%$ meats and starches, $35 \%$ fruits and vegetables, and $20 \%$ fats was assumed. This food mixture, high permittivity and loss, shows absorption near the feed and would improve with multiple excitations. Whereas the low-density polyethylene, LDPE, and polystyrene mixture, low permittivity and loss, has high electric field magnitude throughout the cavity. Despite the high field magnitude the low loss of the material limits the power that can be absorbed and reduces the heating efficiency. 


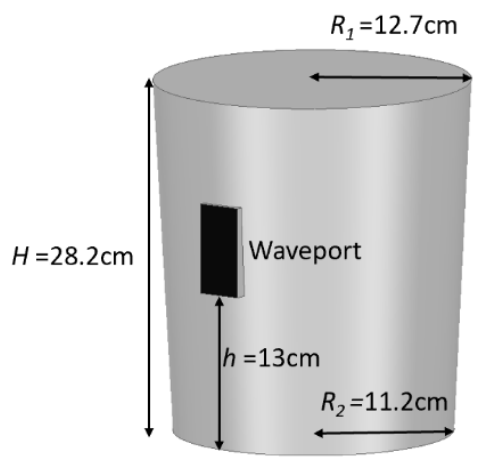

(a)
Magnitude of Electric Field

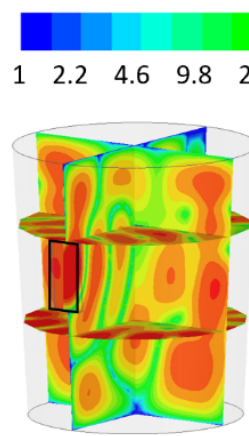

(b)

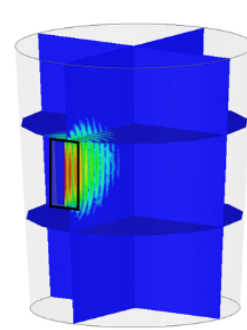

(c)

Fig 2. Simulated magnitude of the electric field for a single waveguide port excitation of a cavity completely filled with various materials. (a) Simulated cavity with dimensions labeled. (b) Cavity filed with food mixture $\varepsilon_{\mathrm{r}}=42$ and $\tan \delta=.3$, and (c) Cavity filled with LDPE and polystyrene $\varepsilon_{r}=2.25$ and $\tan \delta=.0003$. The field value is normalized to a $1 \mathrm{~W}$ incident power at $2.45 \mathrm{GHz}$ on waveguide port.

\section{Thermal Heating Rate Simulations}

The electrical and chemical processes that occur when there is an electromagnetic field inside a material are linked through the heating rate caused by Joule losses as:

$$
\sigma|E(x, y, z)|^{2}=\rho c \frac{d T(x, y, z)}{d t}-\nabla \cdot(\kappa \nabla T(x, y, z))
$$

where $\rho$ is the mass density of the filling material, $c$ is the specific heat of the material, $T$ is the temperature at a specific point within the material, and $\kappa$ is the thermal conductivity. An analytical solution for the heating rate is complicated since the temperature and electric field are functions of position. Therefore, multi-physics simulations were used to determine the temperature increase due to Joule losses and account for the anticipated energy leakage through the cavity walls with thermal insulation as shown in Fig. 3.

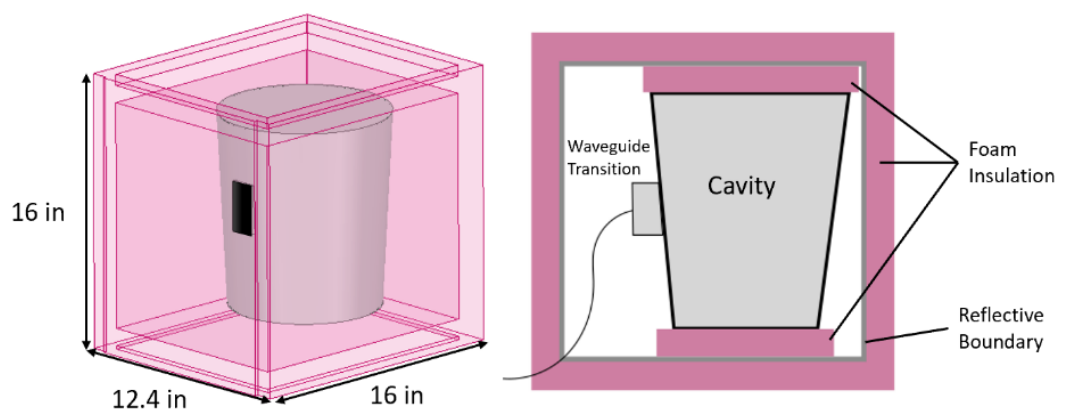

Fig. 3. Image of thermal simulation set up and a side cut of the insulation used in the simulation. The cavity filling is coupled to the field simulation as a thermal source. The cavity walls are $1 \mathrm{~mm}$ thick tin-plated steel, the reflective surround has a reflectivity of $94 \%$ and the foam insulation is 1 in thick XPS rigid polystyrene. 
Using Ansys Workbench to connect the electromagnetic field data from Ansys HFSS and thermal excitation in Ansys Mechanical, heating rates are determined for several input power levels and two internal cavity operating temperatures, the results are shown in Table 1 . These will be used to make an upper estimate of the RF power needed to obtain the specified heating rate required for pyrolysis processes.

Table 1. Simulated heating rates for given material input power and temperature

\begin{tabular}{cccc}
\hline Material & $\begin{array}{c}\text { Input RF } \\
\text { Power }(\mathrm{W})\end{array}$ & $\begin{array}{c}\text { Heating Rate at } 25^{\circ} \mathrm{C} \\
\left({ }^{\circ} \mathrm{C} / \mathrm{min}\right)\end{array}$ & $\begin{array}{c}\text { Heating Rate at } 400^{\circ} \mathrm{C} \\
\left({ }^{\circ} \mathrm{C} / \mathrm{min}\right)\end{array}$ \\
\hline $\begin{array}{c}\text { LDPE and } \\
\text { Polystyrene }\end{array}$ & 500 & .8 & .01 \\
\hline Textiles & 3000 & 5 & 1 \\
\cline { 2 - 4 } & 500 & 16 & 14 \\
\hline Food & 3000 & 75 & 65 \\
\cline { 2 - 4 } & 500 & 100 & 600 \\
\hline Paper & 3000 & 650 & 40 \\
& 500 & 44 & 310 \\
\hline
\end{tabular}

\section{Pyrolysis Process}

The approximation for input materials, output materials, and process requirements for the system are obtained from four reference papers [7-10] which describe pyrolysis for various materials. The cited experiments, with input parameters detailed in Table 2, deal with slow pyrolysis systems that are sealed and operated without catalysts over one hour or longer time periods.

Table 2. Input parameters for several pyrolysis examples with single materials

\begin{tabular}{cccccc}
\hline Material & $\begin{array}{c}\text { Input Caloric } \\
\text { Value } \\
(\mathrm{MJ} / \mathrm{kg})\end{array}$ & $\begin{array}{c}\text { Heating } \\
\text { Rate } \\
\left({ }^{\circ} \mathrm{C} / \mathrm{min}\right)\end{array}$ & $\begin{array}{c}\text { Duration } \\
\text { of Heating } \\
(\mathrm{min})\end{array}$ & $\begin{array}{c}\text { Max } \\
\text { Temperature } \\
\left({ }^{\circ} \mathrm{C}\right)\end{array}$ & $\begin{array}{c}\text { Time at } \\
\text { Max Temp. } \\
(\mathrm{min})\end{array}$ \\
\hline $\begin{array}{c}\text { LDPE and } \\
\text { Polystyrene [7] }\end{array}$ & 44 & 10 & 40 & 425 & 60 \\
Textiles [8] & 28 & 5 & 105 & 550 & 60 \\
Food [9] & 15.7 & 10 & 52 & 500 & 240 \\
Paper [10] & 13.6 & 10 & 85 & 873 & 60 \\
\hline
\end{tabular}

The compounds, composition, and corresponding caloric values of the chemical outputs for the various pyrolysis processes were determined in the references using spectroscopic methods. A summary of the chemical outputs for each process are summarized in Table 3. 
Table 3. Output Parameters for Pyrolysis

\begin{tabular}{ccccccc}
\hline Material & $\begin{array}{c}\text { Gas } \\
\text { Caloric } \\
\text { Value } \\
(\mathrm{MJ} / \mathrm{kg})\end{array}$ & $\begin{array}{c}\text { Percent } \\
\text { weight } \\
\text { Gas } \\
(\%)\end{array}$ & $\begin{array}{c}\text { Oil } \\
\text { Caloric } \\
\text { Value } \\
(\mathrm{MJ} / \mathrm{kg})\end{array}$ & $\begin{array}{c}\text { Percent } \\
\text { weight } \\
\text { Oil } \\
(\%)\end{array}$ & $\begin{array}{c}\text { Biochar } \\
\text { Caloric } \\
\text { Value } \\
(\mathrm{MJ} / \mathrm{kg})\end{array}$ & $\begin{array}{c}\text { Percent } \\
\text { weight } \\
\text { Biochar } \\
(\%)\end{array}$ \\
\hline $\begin{array}{c}\text { LDPE and } \\
\text { Polystyrene }\end{array}$ & 50.8 & 10 & 40.4 & 89.5 & $\mathrm{~N} / \mathrm{A}$ & 0.05 \\
$\begin{array}{c}\text { [7] } \\
\text { Textiles [8] }\end{array}$ & N/A & 45.44 & 11.49 & 24.7 & 31.73 & 13.28 \\
Food [9] & 0.22 & 7.41 & 8.01 & 32.29 & 7.55 & 60.3 \\
Paper [10] & N/A & 15.0 & 21.8 & 19.0 & 11.7 & 43.0 \\
\hline
\end{tabular}

\section{Total Efficiency}

Four different waste materials and mixtures are analyzed and the conversion efficiencies are calculated for filled cavities with dimensions as in Fig.2. The input and output parameters from Tables 2 and 3 are used for the material inside the cavity. The CW RF power required for each waste material to attain the heating rates from Table 2 are estimated by extrapolating the applied power and heating rate simulations from Table 1. Assuming a $70 \% \mathrm{DC}$ to RF efficiency the DC power is calculated for each material. The DC energy is computed by multiplying the DC power by the operating times in Table 2 . The conversion efficiency is defined as

$$
\eta=\frac{W_{C h, O U T}}{W_{C h, I N}+W_{D C}}
$$

where $W_{C h, O U T}$ and $W_{C h, I N}$ are the output and input chemical energies, and $W_{D C}$ is the input dc electrical energy. Fig. 4 shows the simulated electric field magnitude for the 4 cases at $2.45 \mathrm{GHz}$, and Table 4 summarizes the calculated efficiency using equations (2), (3) and (4).

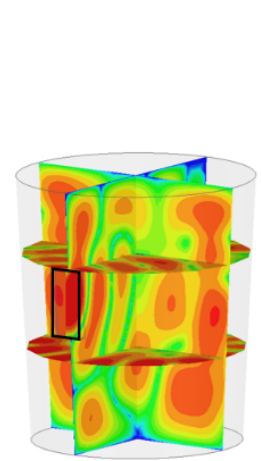

(a)

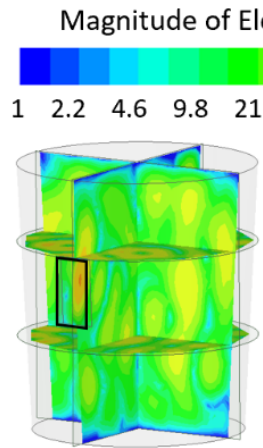

(b)

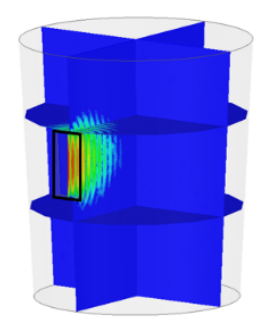

(c)

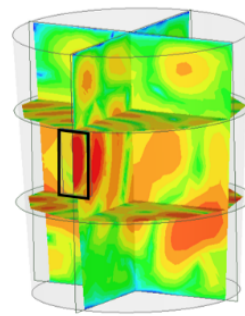

(d)

Fig.1. Simulated magnitude of the electric field, with $1 \mathrm{~W}$ incident power at $2.45 \mathrm{GHz}$, inside cavities completely filled with (a) LDPE and Polystyrene, $\varepsilon_{\mathrm{r}}$ of 2.25, $\tan \delta$ of .0003, thermal conductivity of $.28 \mathrm{~W} / \mathrm{m}^{\circ} \mathrm{C}$, density of $950 \mathrm{~kg} / \mathrm{m}^{3}$ and specific heat of 2300 $\mathrm{J} / \mathrm{kg}^{\circ} \mathrm{C}$, (b) 
Textiles, $\varepsilon_{\mathrm{r}}$ of 3 , tan $\delta$ of .0003 , thermal conductivity of $.05 \mathrm{~W} / \mathrm{m}^{\circ} \mathrm{C}$, density of $1100 \mathrm{~kg} / \mathrm{m}^{3}$ and specific heat of $.33 \mathrm{~J} / \mathrm{kg}^{\circ} \mathrm{C}$, (c) Food mixture, $\varepsilon_{\mathrm{r}}$ of 42 , $\tan \delta$ of .3, thermal conductivity of $.85 \mathrm{~W} / \mathrm{m}^{\circ} \mathrm{C}$, density of $950 \mathrm{~kg} / \mathrm{m}^{3}$ and specific heat of $1.7 \mathrm{~J} / \mathrm{kg}^{\circ} \mathrm{C}$, and (d) Paper, Er of 2.2, $\tan \delta$ of .03 , thermal conductivity of $.05 \mathrm{~W} / \mathrm{m}^{\circ} \mathrm{C}$, density of $1150 \mathrm{~kg} / \mathrm{m}^{3}$ and specific heat of $.33 \mathrm{~J} / \mathrm{kg}^{\circ} \mathrm{C}$.

Table 4. Summary of Full System Efficiencies

\begin{tabular}{cccccc}
\hline Material & $\begin{array}{c}\text { Input } \\
\text { Caloric } \\
\text { Value } \\
(\mathrm{MJ})\end{array}$ & $\begin{array}{c}\text { Output } \\
\text { Caloric } \\
\text { Value } \\
(\mathrm{MJ})\end{array}$ & $\begin{array}{c}\text { DC } \\
\text { Energy } \\
(\mathrm{MJ})\end{array}$ & $\begin{array}{c}\text { Conversion } \\
\text { Efficiency (\%) }\end{array}$ & $\begin{array}{c}\text { Output Energy } \\
\text { compared to } \\
\text { Input DC } \\
\text { Energy (\%) }\end{array}$ \\
\hline $\begin{array}{c}\text { LDPE and } \\
\text { Polystyrene }\end{array}$ & 545 & 548 & 96.8 & 85.4 & 566 \\
Textiles & 480 & 121 & 26.1 & 23.9 & 464 \\
Food & 202 & 92 & 12.2 & 43.0 & 754 \\
Paper & 136 & 92 & 16.0 & 60.5 & 575 \\
\hline
\end{tabular}

\section{Conclusion}

In summary, simulations of microwave heating at $2.45 \mathrm{GHz}$ indicate that it can be effectively used for pyrolysis of various types of waste material. The simulations are performed with a cylindrical thermally-insulated over-moded metal cavity with a single waveguide feed. Future work includes adding more feeds and an investigation power and volume scaling using solid-state sources for smaller volumes and magnetrons for larger volumes where higher power is required.

\section{Acknowledgement}

This work was funded by DARPA under contract W911NF-18-1-0073.

\section{References}

1. D. Czajczyńska, "Potential of pyrolysis processes in the waste management sector," Thermal Science and Engineering Progress, vol. 3, p. 171. Sept., 2017.

2. J.A. Onwudili, "Composition of products from the pyrolysis of polyethylene and polystyrene in a closed batch reactor: effects of temperature and residence time," Journal of Analytical and Applied Pyrolysis, vol. 86 p. 293-303. Nov., 2009.

3. S. Chunshan, "Tri-reforming of methane: a novel concept for synthesis of industrially useful synthesis gas with desired $\mathrm{H} 2 / \mathrm{CO}$ ratios using $\mathrm{CO} 2$ in flue gas of power plants without CO2 separation," Prepr. Pap.-Am. Chem. Soc., Div. Fuel Chem 49, no. 1 (2004): 128.

4. https://www.qorvo.com/products/p/QPD1025

5. H. Jeong, T. Yoon, H. Yoo, H. Jung, S. Cho, "A Highly Efficient and Compact 6kW GaN Solid-State Microwave Generator for CW 2.45GHz Applications," 2019 IEEE International Microwave Symp. (IMS), pp.1-4, June 2019, Boston, U.S.A.

6. C. Liu, H. Huang, Z. Liu, F. Huo and K. Huang, "Experimental Study on Microwave Power Combining Based on Injection-Locked 15-kW S-Band Continuous-Wave Magnetrons," IEEE Transactions on Plasma Science, vol. 44, no. 8, pp. 1291-1297, Aug. 2016. 
7. J.A. Onwudili, "Composition of products from the pyrolysis of polyethylene and polystyrene in a closed batch reactor: effects of temperature and residence time," Journal of Analytical and Applied Pyrolysis, vol. 86 p. 293-303. November, 2009.

8. S. Barış̧1, "The disposal of combed cotton wastes by pyrolysis," International Journal of Green Energy, vol. 11 p. 255-266. June, 2013.

9. S. Opatokun, "Product based evaluation of pyrolysis of food waste and its digestate," Energy, vol. 92 p. 349-354. December, 2015.

10. A. Sarkar, R. Chowdhury, "Co-pyrolysis of paper waste and mustard press cake in a semi-batch pyrolyser-optimization and bio-oil characterization," International Journal of Green Energy, Vol. 13 p. 373-382, October 